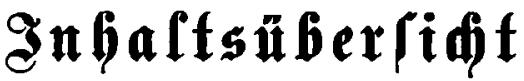

\author{
zum füniten Bande.
}

\section{Fünftę Bưd.}

(10xuredyt.

Einleitung . . . . . . . . . . . . . . . . . . . . . . . 1

Erjter $\mathfrak{A b}\{\dot{d}$ nitt. Grbjolge . . . . . . . . . . . . . . . . 1922-1941 5

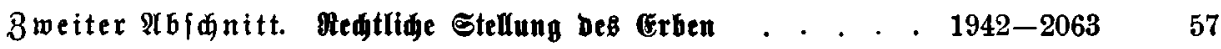

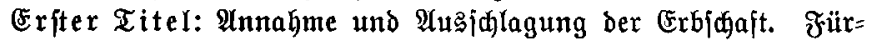

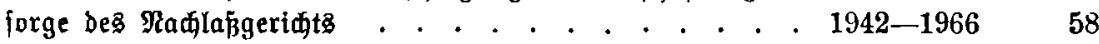

3wetter Titel: Saftung bes Erben für die Radilapberbind=

lidgleiten

I. Radlaßperbinðlidgleiten . . . . . . . . . . 1967-1969 115

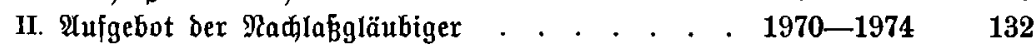

III. Befdränlung Der Şajtung Dę̧ Erben . . . . . . 1975-1992 152

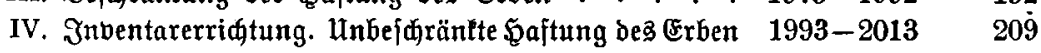

V. Ilufidiebende Einreden . . . . . . . . . . 2014-2017 238

Dritter Titel: Erbjdaftsaniprud $. \quad . \quad . \quad . \quad . \quad . \quad . \quad . \quad . \quad .2018-2031245$

Bierter Titel: Mehrgeit von Erben . . . . . . . . . . 270

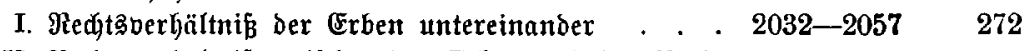

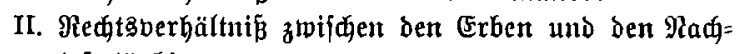
Iaß̧̧ı̆äubigern . . . . . . . . . . . . . 2058-2063 315

Dritter $\mathfrak{A b j} \mathscr{d}$ nitt. Teftament . . . . . . . . . . . . . 2064-2273 326

Expter Titel: 9romeine Borfifriften . . . . . . . . . . . . 2064-2086 327

3weiter Titel: Erbeinjebung. . . . . . . . . . . . . 2087-2099 353

Dritter Titel: Einjezung einea ßađjerben . . . . . . . 2100-2146 363

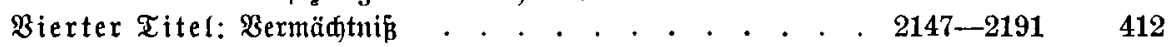

Fünfter Titel: $\mathfrak{A}$ uflage . . . . . . . . . . . . . . . . . . . . 2192-2196 459

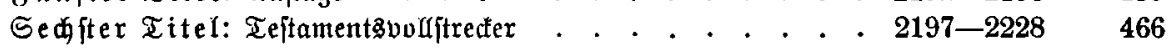

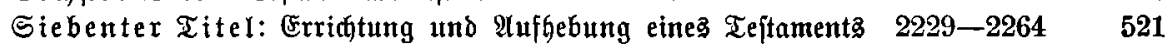

Ad ter Titel: Bemeinjdaftlides Teftament . . . . . . 2265-2273 570

Bierter $\mathfrak{A b}$ dintt. Erbbertrag . . . . . . . . . . . . 2274-2302 584

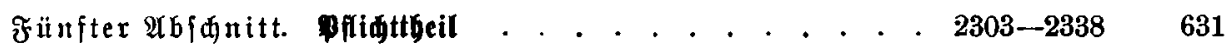

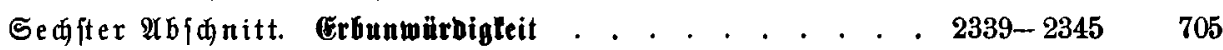

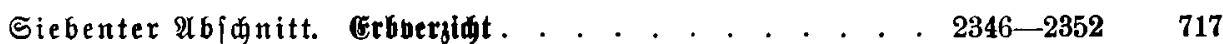

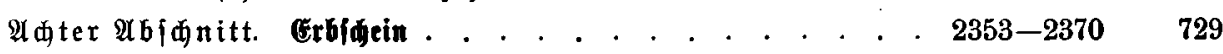

Reunter Abfdnitt. Grbfdaftalauf . . . . . . . . . . . 2371-2385 763

Ulphabetijdes Regifter . . . . . . . . . . . . . . . . . . . . . . 780 
